\title{
Städtische \\ Baum- und Grünflächeninformationssysteme
}

- Ein Beitrag zur stadtökologischen Forschung -

Dissertation zur Erlangung des Doktorgrades der Fakultät für Forstwissenschaften und Waldökologie der Georg-August-Universität Göttingen

vorgelegt von

Thomas Beisch

geboren in Nordkirchen / Westfalen

Göttingen im Juni 1998 
D 7

1. Berichterstatter:

Prof. Dr. A. Akça

2. Berichterstatter:

Prof. Dr. J. Saborowski

3. Berichterstatter:

Prof. Dr. A.W. Bitter

Tag der mündlichen Prüfung: 10. Juli 1998 


\section{Inhaltsverzeichnis}

1. Einleitung $\ldots \ldots \ldots \ldots \ldots \ldots \ldots \ldots \ldots \ldots \ldots \ldots \ldots \ldots \ldots \ldots \ldots$

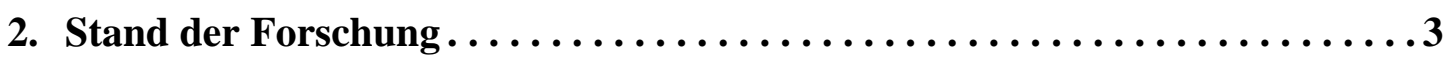

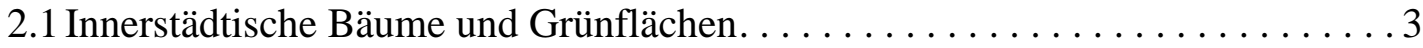

2.11 Geschichtliche Entwicklung innerstädtischer Bäume und Grünflächen . . . . 3

2.12 Wissenschaftliche Ausrichtung der Erforschung innerstädtischer

Bäume und Grünflächen . . . . . . . . . . . . . . . . . . . 4

2.13 Baum- und Grünflächeninformationssysteme $\ldots \ldots \ldots \ldots \ldots \ldots$

2.131 Zum Begriff Baum- und Grünflächenkataster . . . . . . . . . . 7

2.132 Baum- und Grünflächeninformationssysteme in Deutschland . . . . 8 8

2.133 Anforderungen an Baum- und Grünflächeninformationssysteme . . . 13

2.14 Die Anwendung der Luftbildauswertung bei der Erstellung innerstädtischer Baum- und Grünflächenkataster . . . . . . . . . . . . 19

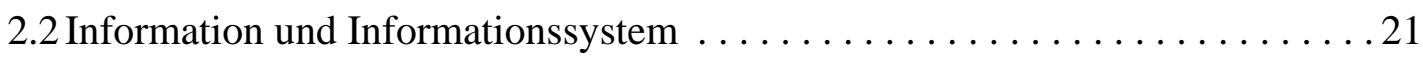

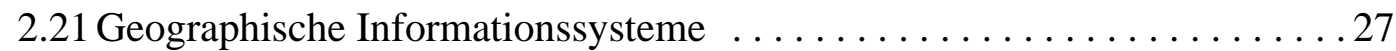

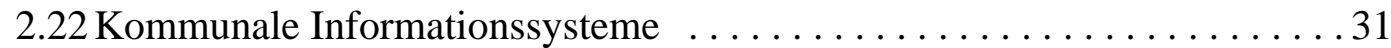

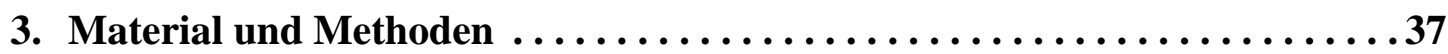

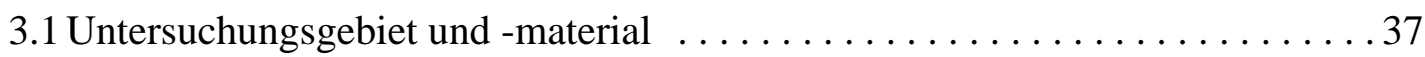

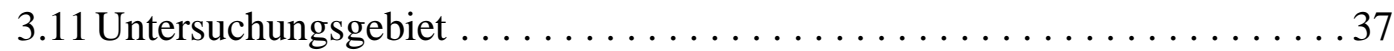

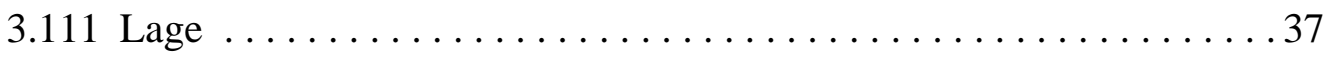

3.112 Geschichte ........................... 38

3.113 Siedlungsökologische Gliederung . . . . . . . . . . . . 39

3.12 Untersuchungsmaterial . . . . . . . . . . . . . . . . . . 44

3.121 Das RING als Basis des Baum- und Grünflächeninformations-

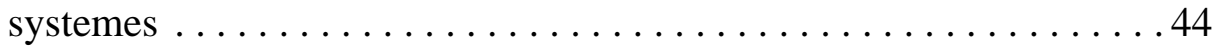

3.122 Luftbildmaterial und Orientierungsgrundlagen $\ldots \ldots \ldots \ldots \ldots 45$

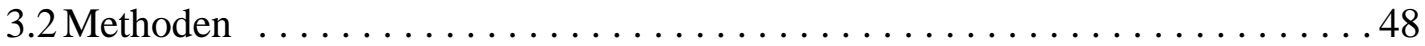

3.21 Geo-Informationssystem und Datenbankmanagement . . . . . . . . . 48

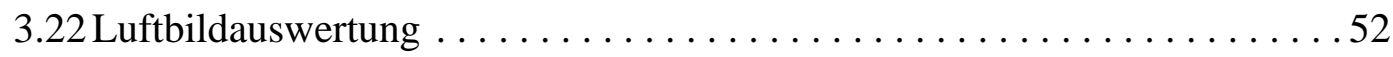

3.221 Grundlagen der Luftbildauswertung $\ldots \ldots \ldots \ldots \ldots \ldots \ldots \ldots \ldots \ldots$

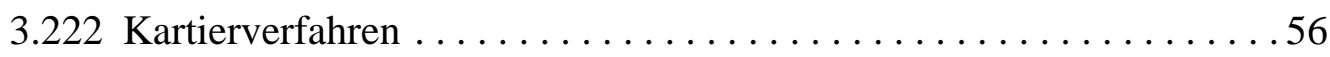

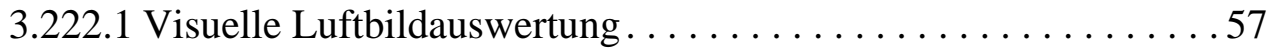

3.222.2 Automatische Luftbildauswertung . . . . . . . . . 61

3.23 Terrestrische Ergänzungsinventur $\ldots \ldots \ldots \ldots \ldots \ldots \ldots \ldots \ldots \ldots$ 
4. Ergebnisse $\ldots \ldots \ldots \ldots \ldots \ldots \ldots \ldots \ldots \ldots \ldots \ldots \ldots \ldots \ldots \ldots \ldots \ldots$

4.1 Baum - und Grünflächeninformationssystem . . . . . . . . . . . . . . . . 79

4.11 Informationsbedarfsanalyse . . . . . . . . . . . . . . . . . . 79

4.12 Konzeptueller Datenbankentwurf . . . . . . . . . . . . . . . . . 81

4.121 Technische Komponente . . . . . . . . . . . . . . . . . . . 81

4.122 Inhaltlich-fachliche Komponente ................. 83

4.13 Logischer und physischer Datenbankentwurf $\ldots \ldots \ldots \ldots . \ldots . \ldots 8$

4.14 Implementierung . . . . . . . . . . . . . . . . . . . . . . . . . . . . 94

4.15 Module des Programmes - Arboretum urbanum . . . . . . . . . . . . . . 97

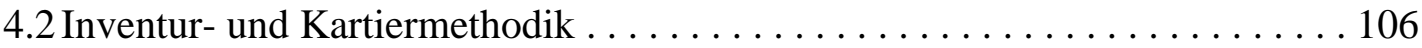

4.21 Luftbildkartierung . . . . . . . . . . . . . . . . . . . . . . . . . . . . 106

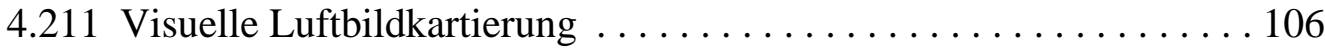

4.211.1 Beziehung zwischen Stammumfang und photogrammetrischen Kronengrößen . . . . . . . . . . . . . . . 110

4.212 Automatische Luftbildkartierung . . . . . . . . . . . . . . . 119

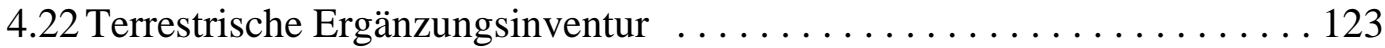

4.3 Anwendungs- und Analysebeispiele . . . . . . . . . . . . . . . . 124

4.31 Retroperspektivische Auswertung . . . . . . . . . . . . . . . . . . . . 124

4.32 Grünanteile der Nutzungs- und Baustrukturtypen . . . . . . . . . . . 131

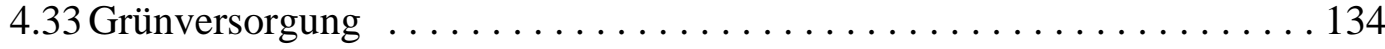

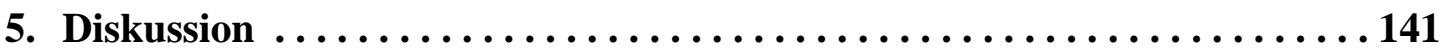

5.1 Baum- und Grünflächenfachinformationssystem . . . . . . . . . . . . . . 141

5.2 Inventurmethodik . . . . . . . . . . . . . . . . . . . 147

5.3 Analyse der Baum- und Grünflächenstruktur $\ldots \ldots \ldots \ldots \ldots \ldots \ldots \ldots \ldots \ldots$

6. Ausblick .......................................... 155

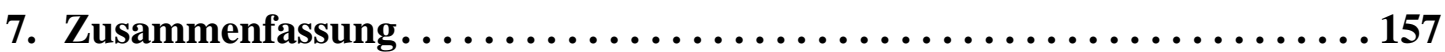

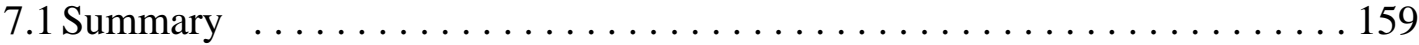

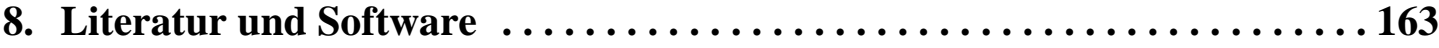

8.1 Literatur . . . . . . . . . . . . . . . . . . . . . . . . . . . . 163

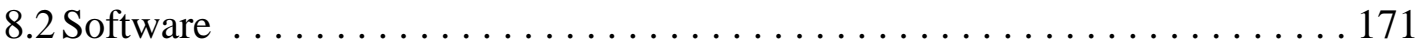

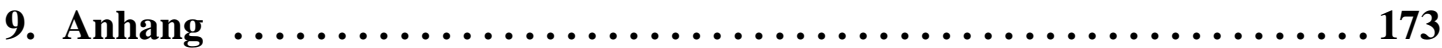

9.1 Lebenslauf . . . . . . . . . . . . . . . . . . . . . . . . . . . . . . . . . . . . 173 